\title{
Application of neural network technology to calculate well logging porosity on the example of UK2-7 formations in the Yelizarovsky deflection (Western Siberia)
}

\author{
E.A. Lisovskaya, B.V. Platov \\ Kazan Federal University, Kazan, Russia
}

\begin{abstract}
The article describes the use of an artificial neural network to calculate porosity in the West Siberian oil and gas province for the $\mathrm{UK}_{2-7}$ strata. The estimated porosity was compared with core porosity data. Correlation coefficient between core samples porosity and well logging porosity (using the neural network) showed higher values in comparison with traditional methods of porosity estimation.
\end{abstract}

\section{Introduction}

Improving the accuracy of porosity determination by well-logging data in a productive reservoir is an important task in the oil and gas field development for the calculation of oil and gas reserves.

The deposits of Western Siberia are complicated by a series of tectonic disturbances of the pre-Jurassic and Jurassic ages of the North-Western and North-Eastern strike. Along with large faults, the study area includes a developed system of small faults that emphasize the local block structure of the basement [1].

Thus, strata confined to the side of the Elizarovsky deflection are difficult for determining porosity due to geological variability. Nevertheless, the importance of developing this field is determined by the fact that in the deepest synclines, under severe conditions of high reservoir pressures and temperatures, the generation of hydrocarbons (HC) is more intense than in higher areas. The industrial oil content of the Tyumen formation is associated with the presence of low-thickness layers in the section. These layers have a pore-crack character of porosity and reach 16\%. Quantitative assessment of reservoir properties is difficult due to the diversity of the lithological composition of rocks.

The standard approach of defining petrophysical equations between the porosity of core samples (laboratory study of the core) and porosity obtained by well logging methods shows a low correlation coefficient.

Therefore, it is necessary to search for alternative approaches to find porosity from well logging data. In this paper, the authors evaluate the use of an artificial neural network to construct an algorithm for well-logging data interpretation for the $\mathrm{UK}_{2-7}$ strata in the West Siberian oil and gas province. 


\section{Methods for porosity determination from well-logging data}

\subsection{Traditional methods}

The work was performed based on data on a well located in the side part of the Yelizarovsky deflection of the West Siberian field. The well-logging data comprised acaliper, GR $\log$, neutron $\log$, density $\log$, apparent resistivity $\log$, and induction $\log$. The data, as well as the results of the study of the core (61 samples), were taken from the following intervals: 2766.3-2785.97 m (SK2-3), 2788.6 - $2796.9 \mathrm{~m}$ (SK4), 2805.7 - 2813.9 m (SK5), 2816.5 - 2842m (SK6), which belong to the Tyumen Suite.

Porosity was determined bythe following methods:

1. Using standard field equations.

The standard equations for this field are based on the density and GR logs:

$$
\begin{gathered}
\Phi(\text { density })=\left(2.72-\rho_{\text {bulk }}\right) /(2.72-1) \\
\Phi(\mathrm{GR})=-11.979 \Delta J_{\gamma}+15.771
\end{gathered}
$$

2. Using created equations (direct core-well log correlation).

Adirect correlation between core porosity andwell logging values was calculated for the interval with the core samples. The highest correlation was found between coreporosity and values of the density log.

The relationship between core porosity and well logging data was obtained for both approaches, but the values of correlation were low. The advantages of traditional methods areindustry-approved and easy to use( since no special software is required). In the simplecases, it gives good results, but in more complex cases, like the Yelizarovsky deflection, the results are not accurate.

Thus, the authors searched for alternative approaches for finding porosity from welllogging data.

\subsection{Artificial neural networks}

Recently, several researchers have proposed to evaluate the possibility of using selflearning artificial neural networks to process exploration data [2, 7].

There are three learning models: "supervised", "unsupervised" (self-learning), and mixed [3]. To solve the problem of finding the best porosity value givenin this article, the supervised model was used. This means that during training the neural network relayed the"correct answers" for input data. In the process of learning, the weights of connections between neurons in the network were adjusted so that the network would give the answersclosest to the available "correct answers". The neural network application scheme is shown in Figure 1. 


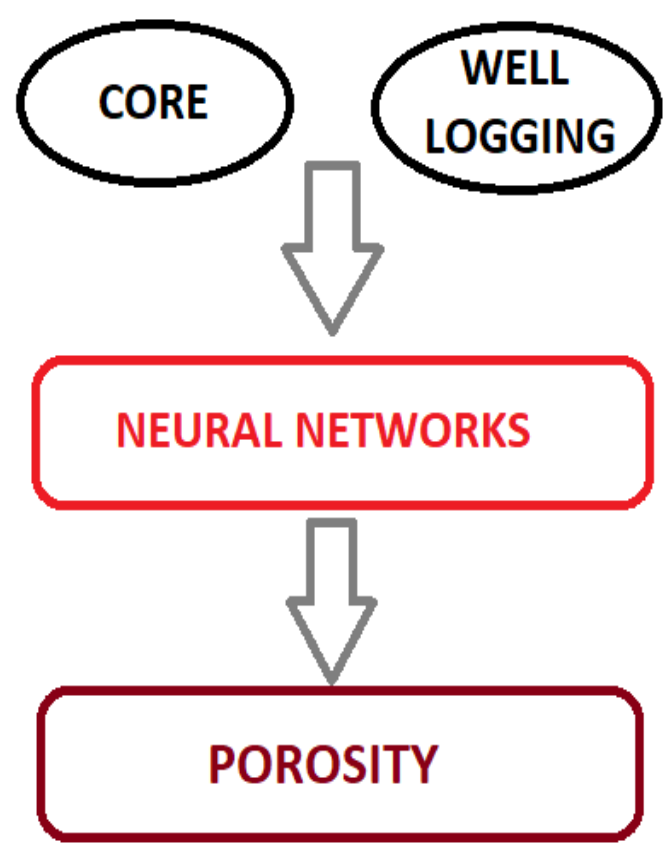

Fig. 1. The principal scheme of the neural network.

Neural network algorithms are actively used in geology to solve all sort of problems[2, $4,5,6,8,9]$.

In this regard, the authors evaluated the use of artificial neural networks to construct an algorithm for well-logging data interpretation.

The neural network was trained on the porosity of core samples to look for hidden relationships between core and well logs. All calculations were performed in the Petrel 2018 software with the standard procedure of train estimation model. It uses a multilayer perceptron network with hidden layers. This network is based on a backpropagation algorithm where the network has one or more hidden layers and it is successfully used to solve different estimation and classification problems [2].

The authors used supervised estimation, where the neural network was trained on the core porosity data, and tried to represent it with a set of well logs. The parameters for the neural network training were: max number of iterations - 30, error limit - $10 \%$, cross validation $-50 \%$. A neural network with these parameters gives the best results and avoids overtraining with the limited dataset (the authors used 61 core samples).

To evaluate the influence of different well logs on the results, authors ran the sensitivity analysis. The goal was to find the most important input data for porosity calculation and exclude well logs that make an additional error.

Initially the neutron network included logs:

- Gammaray log (GR)

- Spontaneous potential $\log (\mathrm{SP})$

- Neutron thermal log

- Density log

- Apparent resistivity log - Potential probe (PZ)

- Apparent resistivity log - Gradient probe (GZ)

- Induction log. 
The porosity values calculated using a neural network were compared with the porosity values of the core samples.

\section{Results}

To evaluate the reliability of the determined well logging porosity, it was compared with core samples' porosity.

\subsection{Traditional methods}

Porosity, calculated using standard equations for the oilfield using the GR and density logs, was compared with core samples porosity (Figure 2).

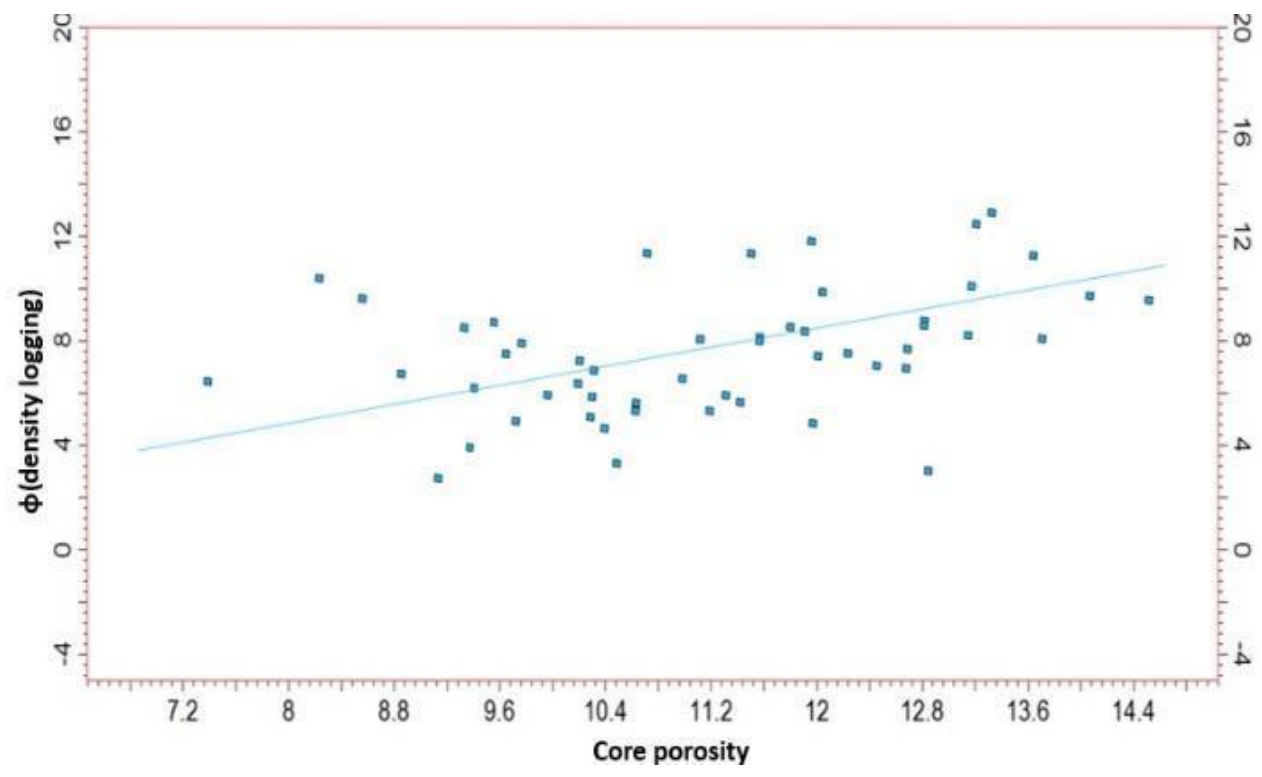

Fig. 2. Correlation between porosity calculated using the standard equation for density log and core samples porosity.

The authors used Pearson's correlation coefficient formula:

$$
\mathrm{R}=\sum\left(\mathrm{xi}-\mathrm{x}_{\text {mean }}\right) *\left(\mathrm{yi}-\mathrm{y}_{\text {mean }}\right) /\left(\sqrt{ } \sum\left(\mathrm{xi}-\mathrm{x}_{\text {mean }}\right)^{2} * \sqrt{ } \sum\left(\mathrm{yi}-\mathrm{y}_{\text {mean }}\right)^{2}\right)(3)
$$

where $\mathrm{x}$ arethe values of core samples porosity, $\mathrm{y}$ are thevalues of porosity, calculated using the standard equation for density log.

The correlation coefficient for the $\mathrm{UK}_{2-7}$ layers $\mathrm{R} \approx 0.16$ and $\mathrm{R} \approx 0.22$ were obtained for the GR and density logs, respectively. This indicates a very low connection between the data.

The authors attempted to find a direct relationship between the GR and density logs and the core porosity. The result shows that the correlation coefficients are $\mathrm{R} \approx 0.2$ and $\mathrm{R} \approx 0.41$ for GR and density logs, respectively. Figure 3 shows the correlation between density logs and core data. 


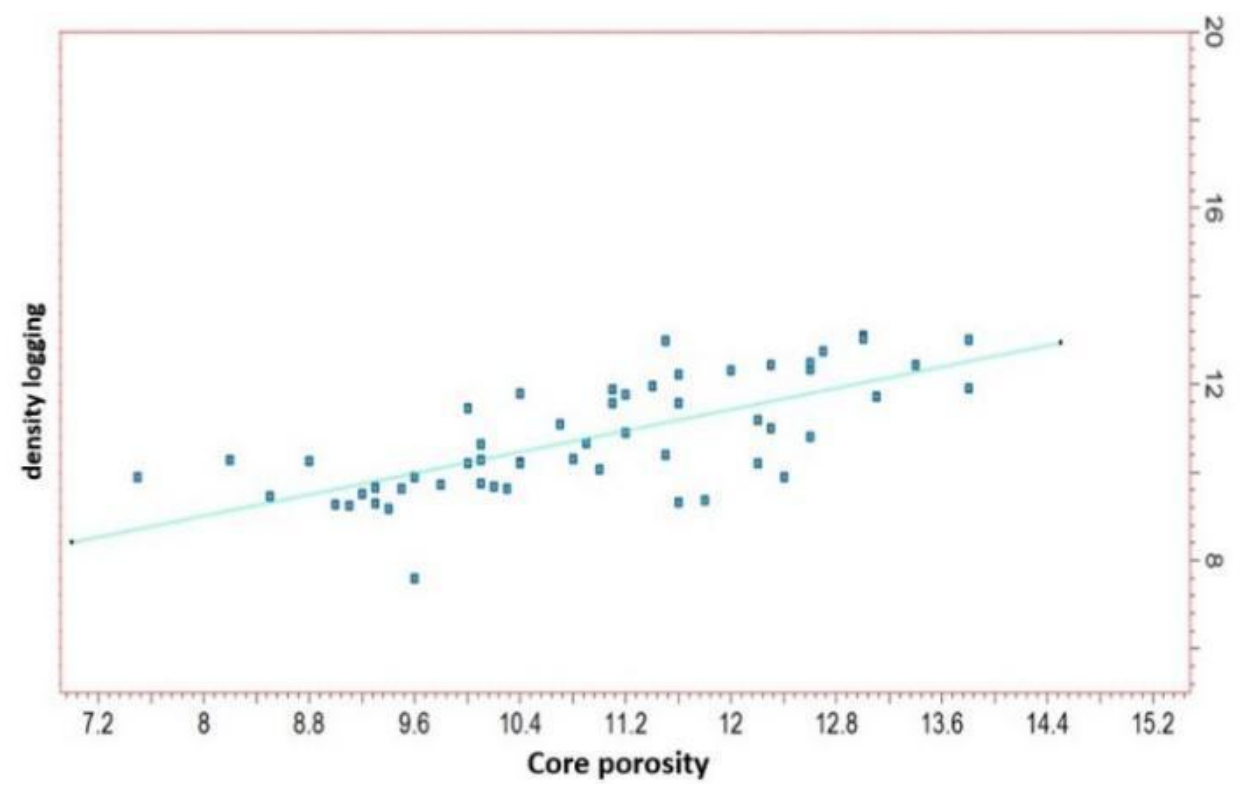

Fig. 3. Correlation between density logs and core porosity data.

Both traditional methods failed to give a correct estimation of porosity.

\subsection{Artificial neural networks}

Initially, the creation of a neural network included the entire set of well logs. This resulted in the correlation coefficient $\mathrm{R} \approx 0.523$ between the porosity calculated using a neural network and the core, which indicates a stronger correlation of values than the traditional approach (Figure4).

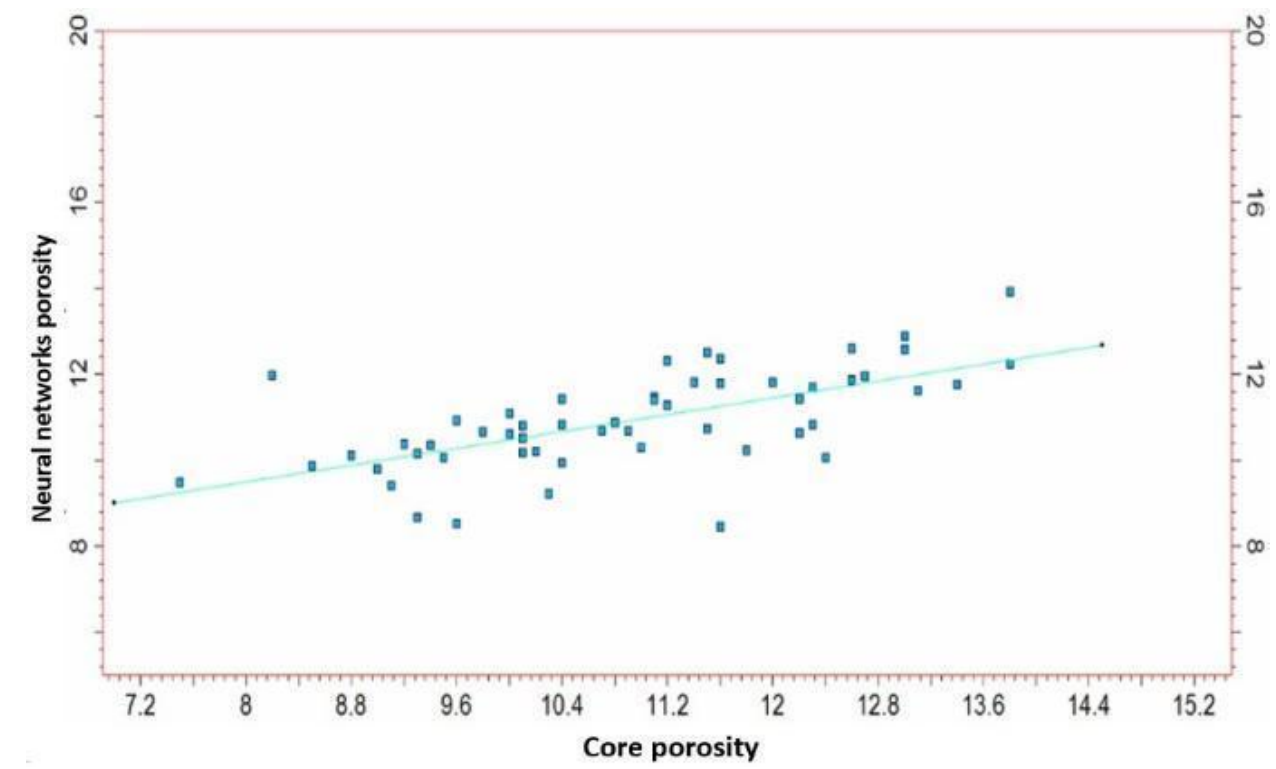

Fig. 4. Correlation between porosity calculated using the neural network (all well logs) and the core porosity data. 
Next, the influence of different logging methods on the output data on the neural network was considered.

The greatest influence on the porosity determined by the neural network has:

- Gammaray $\log (\mathrm{GR})$

- Neutron thermal log

- Density log

- Apparent resistivity log - Potential probe (PZ).

The next task was to analyze the sensitivity of the resulting neural network when using selected logs.

The density log has the greatest influence on porosity In this regard, it is necessary to include this method in the set of well logs for creating a neural network for calculating porosity Incaseof the absence of the density log,the correlation is reduced to $\mathrm{R} \approx 0.448$.

The neutron method is slightly more important for a neural network.In the absence of this method, the correlation is $\mathrm{R} \approx 0.557$.

Data from GR and apparent resistivity logs have less influence. The resulting correlation is $\mathrm{R} \approx 0.63$ and $\mathrm{R} \approx 0.61$, respectively.

Thus, a set of well logs for building a neural network was obtained, which provides the best correlation between obtained well logging porosity and core samples porosity $\mathrm{R} \approx 0.723$. This correlation is shown in Figure 5 .

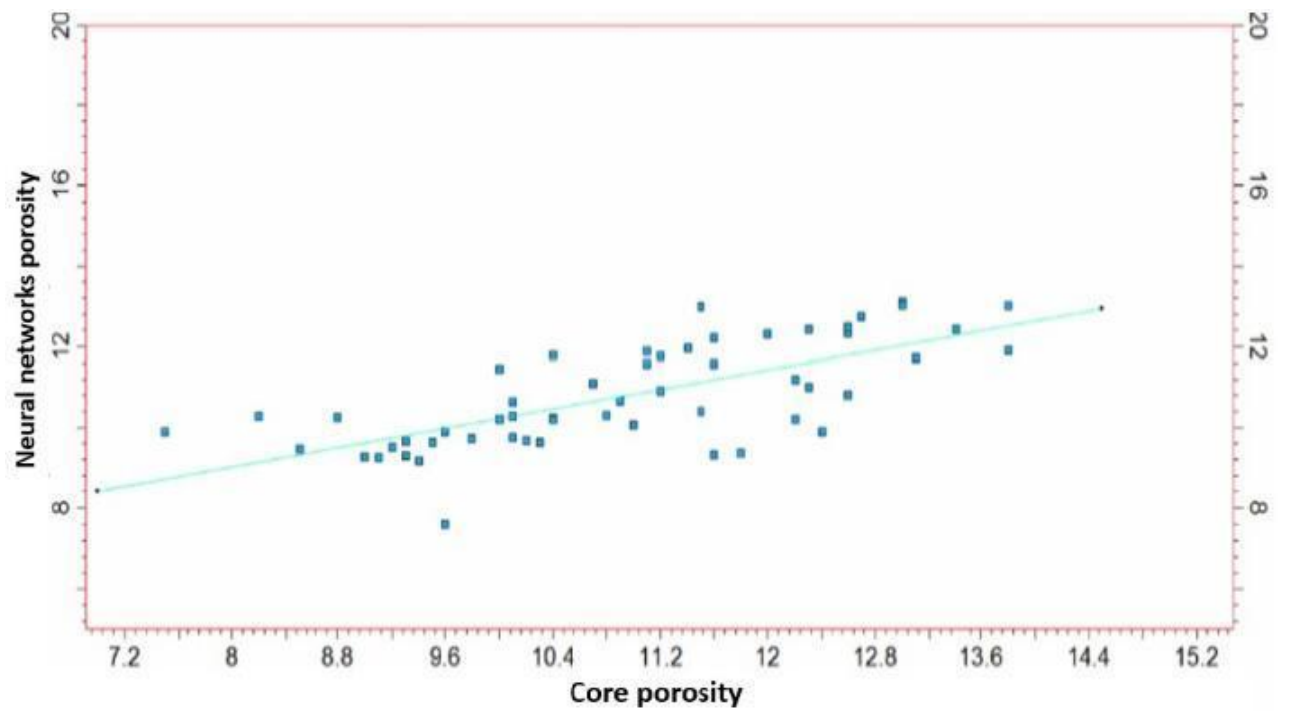

Fig. 5. Correlation between porosity calculated using the neural network and core porosity data.

\section{Conclusions}

Several conclusions can be made.

The standard approach for porosity calculation for reservoirs of the Yelizarovsky deflection is not sufficiently accurate. The correlation coefficient using neural networks (from $\mathrm{R} \approx 0.4$ to $\mathrm{R} \approx 0.718$ ) in comparison with the traditional interpretation $(\mathrm{R} \approx 0.2)$ showed higher values of $\mathrm{R}$, which indicates a closer connection between the data.

A set of well logs (GR, neutron, density, apparent resistivity) for the neural network construction was determined, which provides the best correlation of the obtained porosity with the core data $\mathrm{R} \approx 0.718$. 
The work was supported by the Ministry of Science and Higher Education of the Russian Federation contract No.14.Y26.31.0029 in the framework of the Resolution No.220 of the Government of the Russian Federation

The authors express their deep gratitude to the employees of RITEK, S. A. Kharlanov, V. I. Radishchev, and N. M. Nikolayev for their support and the geophysical data provided for analysis.

\section{References}

1. Yuriev, A.V., Gurbatova P., Melekhin S. V. Geology, Geophysics and development of oil and gas structures Features of studying petro physical and elastic properties of the core in complex reservoirs of oil and gas when modeling thermo baric formation conditions5, 67-72 (2010).

2. Du KL.,Swamy M.N.S. Springer Fundamentals of Machine Learning. In: Neural Networks and Statistical Learning(2014).

3. Hamada, G., Elsakka A. Petroleum engineering department, Faculty of geosciences and petroleum engineering, University technology Petronas Artificial neural network (ann) prediction of porosity and water saturation of Shaly sandstone reservoirs, Malaysia (2018)

4. Hertz, J. Krogh, A., Palmer, R. PressWestviewIntroduction to the theory of neural computation(1991).

5. Murtazin T., Ismagilov A., Novikiva S., Sudakov V. SGEM Methods of automation the process of detailed correlation of well sections with the use of machine learning (2019)

6. Platov, B., Kozhevnikova, N., Shipaeva, M. SGEMThe example of neural net algorithm applying for seismic facies analysis. Example from the republic of Tatarstan (2019)

7. Platov, B., Safina, R., Zinjukov, R. SGEM Seismic facies analysis of the carboniferous reservoir. Case study from the Tatarstan(2018)

8. Podolsky, A.K. Modern scienceApplication of artificial intelligence methods in the oil and gas industry3, 33-36 (2016).

9. Stepanov A., Murtazin T., Ismagilov A., Delev A., SGEM Use of an artificial neural network algorithm and cokriging method for reservoir porosity modeling (2019)

10. Validov, M., Ismagilov, A.R., Voloskov, D, Magdeyev, M.S., Nazarov, A.A. EAGE Geomodel Development of the Approach for Automatic Well Logging Interpretation for Big Number of Wells with the Use of Machine Learning (2017)

11. Yang Yu.,Aplin A.C., Larter S.R. Petroleum geoscienceQuantitative assessment of mud-stone lithology using geophysical wireline logs and artificial neural networks10,141-151 (2004). 